\title{
Early Alterations of Growth Factor Patterns in Bronchoalveolar Lavage Fluid From Preterm Infants Developing Bronchopulmonary Dysplasia
}

\author{
JASPER V. BEEN, ANNE DEBEER, J. FREEK VAN IWAARDEN, NICO KLOOSTERBOER, VALÉRIA LIMA PASSOS, \\ GUNNAR NAULAERS, AND LUC J. ZIMMERMANN
}

\begin{abstract}
Department of Paediatrics [J.V.B., J.F.v.I., N.K., L.J.Z.], Maastricht University Medical Centre, Maastricht 6202 AZ, The Netherlands; Department of Neonatology [A.D., G.N.], University Hospital Gasthuisberg, Leuven 3000, Belgium; Department of Methodology and Statistics [V.L.P.], Maastricht University, Maastricht 6200 MD, The Netherlands
\end{abstract}

\begin{abstract}
Chronic lung disease of prematurity (bronchopulmonary dysplasia; BPD) is characterized by an arrest in lung development. We hypothesized that early alterations in pulmonary expression of growth factors important for normal lung development would precede development of BPD. Bronchoalveolar lavage fluid (BALF) was obtained from ventilated preterm infants $(n=62)$ on postnatal d $0,1,3$, and 7 and analyzed for total phospholipids (PL), VEGF, PDGF-BB, TGF- $\alpha$ and $-\beta 1$, granulocyte macrophage colony stimulating factor (GM-CSF), and keratinocyte growth factor (KGF). Levels (Ln transformed) were compared between infants developing BPD and BPD-free survivors, adjusted for potential confounders. BPD was associated with higher overall GM-CSF $(\beta(95 \% \mathrm{CI})=$ $0.69(0.13 ; 1.25) ; p<0.05)$, lower overall latent TGF- $\beta 1$ ( $\beta(95 \%$ $\mathrm{CI})=-1.19(-1.87,-0.39) ; p<0.01)$ and total PL $(\beta(95 \% \mathrm{CI})=$ $-0.64(-1.23,-0.05) ; p<0.05)$, and lower $\mathrm{d} 0$ and 3 levels of VEGF (mean difference $(95 \% \mathrm{CI})=-1.75(-2.72,-0.77), p<$ 0.001 ; and $-1.18(-2.30,-0.06), p<0.05$, respectively) and TGF- $\alpha$ (mean difference $(95 \% \mathrm{CI})=-0.73(-1.42,-0.04), p<$ 0.05 ; and $-1.01(-1.64,-0.38), p<0.01$, respectively). Day 0 VEGF levels had the highest predictive value for BPD (area under receiver operating characteristic curve $=0.87 ; p<0.01$ ). In conclusion, substantial alterations in BALF growth factor levels are present in infants developing BPD. An early imbalance in pulmonary growth factors may contribute to the developmental arrest of the lung seen in BPD. (Pediatr Res 67: 83-89, 2010)
\end{abstract}

B ronchopulmonary dysplasia (BPD) is a chronic lung disease seen in preterm infants, affecting around $35 \%$ of extremely low-birth weight infants. BPD is associated with recurrent respiratory infections, frequent rehospitalization, and adverse neurodevelopmental outcome. The classical BPD picture of emphysema, inflammation, and fibrosis, as originally described by Northway et al. (1), has been replaced by one best characterized as an arrest in lung development (2). This shift coincided with the introduction of surfactant replacement therapy and antenatal steroid administration, which have allowed smaller and less mature infants to survive.

Received May 1, 2009; accepted September 6, 2009.

Correspondence: Jasper V. Been, M.D., Department of Paediatrics, Maastricht University Medical Centre, PO Box 5800, 6202 AZ Maastricht, The Netherlands; e-mail: jasper.been@mumc.nl

Supported by grants from ZonMW and Profileringsfonds (Maastricht University Medical Centre).
The pathophysiology of BPD is complex and is an interplay between iatrogenic injury due to both mechanical ventilation and oxygen supplementation and other factors such as genetic predisposition and inflammation (3). The latter has been shown to predispose the infant to BPD already before birth, as indicated by the relationship between chorioamnionitis and adverse lung development $(4,5)$. In recent years, accumulating evidence indicates that growth factors play an important role in the developmental arrest of the lung seen in "new BPD" $(3,6)$. However, much of this evidence is derived from experimental animal data. Studies on pulmonary growth factor concentrations and indicators of lung maturation in preterm infants are scarce. Most of them report on analyses on tracheal aspirate fluid (TAF), retrieving epithelial lining fluid of more proximal origin than bronchoalveolar lavage (BAL) (7). Moreover, very few studies have investigated concurrent coexpression of various growth factors in human specimens.

The objective of this study was to simultaneously quantify concentrations of several growth factors in BAL fluid (BALF) obtained from ventilated preterm infants during the first week after birth. Growth factors were selected based on their previously demonstrated roles in lung development and chronic lung injury. VEGF is a known stimulant of alveolarization and vascularization and is invaluable for normal lung development $(3,8)$. Keratinocyte growth factor (KGF) is an epithelial mitogen with an important role in lung injury repair (9), while PDGF-BB has been linked to compensatory lung growth (10), in addition to adverse lung development and fibrosis (11). The hematopoietic cytokine granulocyte macrophage colony stimulating factor (GM-CSF) is up-regulated by inflammation (12) and plays an important role in surfactant homeostasis (13). TGF- $\alpha$ disrupts lung morphogenesis in mice (14) and has been implicated in the pathogenesis of BPD (15). Finally, TGF- $\beta 1$ is a cytokine essential for normal lung development (16), although its overexpression decreases alveolarization in animal models (17). It was hypothesized that early differences in BALF expression patterns of these growth factors would be

Abbreviations: AUC, area under the curve; BALF, bronchoalveolar lavage fluid; BPD, bronchopulmonary dysplasia; GM-CSF, granulocyte macrophage colony stimulating factor; KGF, keratinocyte growth factor; PDGF-BB, platelet derived growth factor BB; PL, phospholipids 
present between infants who eventually developed BPD and those who did not. In addition, we quantified BALF total phospholipids (PL) as a general measure of lung maturation.

\section{MATERIALS AND METHODS}

Patient characteristics and enrollment. Patients were eligible for the study if they were born before 32-wk gestational age and ventilated for respiratory distress syndrome (RDS). Patients were enrolled in the NICUs of the University Hospitals in Maastricht and Leuven. The Medical Ethical Committees of both hospitals have approved the study and written parental consent was obtained. BPD was diagnosed according to Jobe and Bancalari (18). Chorioamnionitis was diagnosed histologically when $>10$ neutrophils per high power field were present in the chorion or amnion. Betamethasone $(2 \times 12 \mathrm{mg}$ i.m., $24 \mathrm{~h}$ apart $)$ was administered to the mother in case of imminent preterm delivery.

BALF collection and processing. BAL was performed at postnatal d 0 (within $24 \mathrm{~h}$ after birth), 1, 3-4, and 7 according to a standard procedure. After turning the infant's head to the left, a $6 \mathrm{~F}$ suction catheter was inserted through a side port of the Trachcare closed suctioning system until slight resistance was felt. Then, $1 \mathrm{~mL} / \mathrm{kg}$ birth weight of sterile isotonic saline was gently infused into the lung. After $5 \mathrm{~s}$, suctioning was performed while slowly retracting the catheter. The procedure was repeated once after which the collected fluid was pooled and placed on ice. After centrifugation for $10 \mathrm{~min}$ at $4^{\circ} \mathrm{C}$ and $300 \times \mathrm{g}$, the supernatant was collected, aliquoted, and stored at $-80^{\circ} \mathrm{C}$ until analysis.

Quantification of growth factors and total PL in BALF. VEGF, KGF, PDGF-BB, GM-CSF, TGF- $\alpha$, and TGF- $\beta 1$ and were quantified by ELISA (R\&D systems, Minneapolis, MN) according to the manufacturer's instructions, in half-area 96-well ELISA plates (Greiner Bio-one, Alphen a/d Rijn, The Netherlands). Both active and total (latent + active) TGF- $\beta 1$ were quantified. The concentration of latent TGF- $\beta 1$ was obtained by subtracting the amount of active TGF- $\beta 1$ from the total TGF- $\beta 1$, quantified after acidactivation of each individual sample.

As a general measure of BALF surfactant content, total PL were quantified according to Stewart (19), with minor modifications to analyze small quantities. Briefly, fluid was evaporated from $15 \mu \mathrm{L}$ of BALF by heating at $50^{\circ} \mathrm{C}$ under continuous nitrogen gas flow. The dried material was reconstituted in $100 \mu \mathrm{L}$ of chloroform and vortexed. Then, $50 \mu \mathrm{L}$ of ammonium ferrothiocyanate was added, and the mixture was vortexed thoroughly for $30 \mathrm{~s}$. The organic phase (containing the stained PL) was separated from the inorganic phase by centrifugation (10 min, $2000 \mathrm{rpm}$ ). Then, $75 \mu \mathrm{L}$ of the organic phase of each sample was transferred into a 96-well glass-coated microtiter plate (Instrument Solutions, Nieuwegein, The Netherlands), and extinction was measured at $488 \mathrm{~nm}$ in a Spectra Max M2 photospectrometer using a phosphatidylcholine standard curve (range, $0-200 \mu \mathrm{g} / \mathrm{mL}$ ). Growth factor and PL concentrations were considered detectable when they were above background levels of their respective assays. All concentrations are expressed per milliliter of BALF retrieved according to European Respiratory Society task force guidelines (20).

Univariable analyses. Data are expressed as mean $\pm \mathrm{SD}$ or median with interquartile range (IQR) where appropriate. Correspondingly, differences between groups were tested using either $t$ test or Mann-Whitney $U$ test. Dichotomous variables were tested using $\chi^{2}$ test. Correlations between variables were determined using Spearman's $\rho$ correlation coefficient.

Multivariable analyses-the marginal model. To obtain a more symmetric distribution of the positively skewed growth factor levels while appreciating undetectable levels (which were entered as " 0 "), concentrations were transformed using the following formula: Ln ([growth factor] +1 ). Marginal models were fitted to evaluate average changes in transformed growth factor concentrations over time between infants with or without BPD, adjusting for other potential confounders (21). Individual infants were taken as random factor and time (categorized) as well as the other explanatory variables constituted the model's fixed effect part. A top down procedure was handled for variable selection, except for BPD and gestational age, which were always kept in the model. Model parameters were estimated via the restricted maximum likelihood method. The final variance-covariance matrix was selected via likelihood ratio tests. Based on the estimated mean transformed growth factor values, Bonferroni post hoc analysis was applied for multiple pairwise comparisons between groups and time points. For marginal model analysis, infants with mild, moderate, and severe BPD were clustered in a single BPD category. Antenatal betamethasone exposure was categorized according to time between exposure and birth $(<24 \mathrm{~h}, 2-7 \mathrm{~d}$, and $>7 \mathrm{~d})$.

One of the advantages of the marginal model analysis is that all individual data are used for the parameters estimation, not only of those subjects with complete data (21). To check whether the occurrence of missing values depended on the predictors at stake, a logistic regression model was applied. Explanatory variables significantly associated with missingness were kept in the final marginal model.

Multivariable analyses-logistic regression for prediction of BPD. Backward logistic regression analysis was performed to evaluate which combination of growth factors in BALF best predicted the development of BPD at each postnatal day. Receiver operating characteristic (ROC) curves for BPD prediction were computed using individual predicted probabilities derived from the final logistic regression model. In all analyses, an alpha level of 0.05 was applied (two-tailed). All analyses were performed using SPSS 15.0 software.

\section{RESULTS}

General characteristics. One hundred twenty-one BALF specimens were obtained from 62 patients. At 36-wk PMA, 34 patients fulfilled the diagnostic criteria of BPD. In further analyses, the latter are compared with patients alive without BPD at 36-wk PMA $(n=21)$. Seven patients had died and were excluded from further analyses. General characteristics, ventilatory settings, and oxygen requirement for patients with and without BPD are shown in Table 1. Infants who developed BPD were more often born to mothers with preeclampsia, had lower birth weight, and had higher oxygen requirement just before BALF collection on $\mathrm{d} 0$ and 1 .

Univariable analyses. Growth factor and total PL concentrations for infants who did and those who did not develop BPD are shown in Table 2. In unadjusted analyses, patients developing BPD had lower VEGF on d 0 and 3, lower TGF- $\alpha$ on $\mathrm{d} 0$, and latent TGF- $\beta 1$ on $\mathrm{d} 0$. Conversely, both GM-CSF and active TGF- $\beta$ were more likely to be detected in infants developing BPD on $d$ 7. Infants with BPD had a higher active

Table 1. General characteristics and ventilatory requirements of infants included in the study

\begin{tabular}{lcc}
\hline & $\begin{array}{c}\text { No BPD } \\
(n=21)\end{array}$ & $\begin{array}{c}\text { BPD } \\
(n=34)\end{array}$ \\
\hline Gestational age (wk) & $29.0 \pm 1.8$ & $28.0 \pm 1.8$ \\
Birth weight (g) & $1212 \pm 136$ & $1005 \pm 263^{*}$ \\
Histological chorioamnionitis (\%) & 19 & 17 \\
Preeclampsia (\%) & 10 & $38 \dagger$ \\
Antenatal steroids & & \\
$<24$ h before birth & 33 & 24 \\
1-7 d before birth & 14 & 38 \\
$>7$ d before birth & 33 & 27 \\
Mean FiO ${ }_{2}$ 0 to 6 h before BAL (\%) & & \\
d 0 & $28 \pm 10$ & $52 \pm 25 \ddagger$ \\
d 1 & $25 \pm 5$ & $32 \pm 10 \dagger$ \\
d 3 & $25 \pm 7$ & $27 \pm 6$ \\
d 7 & $24 \pm 3$ & $26 \pm 6$ \\
Mean MAP 0 to 6 h before BAL (cm $\left.\mathrm{H}_{2} \mathrm{O}\right)$ & & \\
d 0 & $8.8 \pm 2.4$ & $8.6 \pm 2.4$ \\
d 1 & $8.2 \pm 2.7$ & $8.3 \pm 2.4$ \\
d 3 & $7.9 \pm 2.0$ & $8.2 \pm 2.4$ \\
d 7 & $8.3 \pm 2.0$ & $9.2 \pm 1.9$ \\
BALF specimens collected (n) & & \\
d 0 & 11 & 14 \\
d 1 & 9 & 24 \\
d 3 & 13 & 20 \\
d 7 & 3 & 13 \\
\hline
\end{tabular}

$* p<0.001$.

$\dagger p<0.05$.

$\ddagger p<0.01$.

$\mathrm{FiO}_{2}$, fraction of inspired oxygen; MAP, mean airway pressure. 
Table 2. Growth factor and total phospholipids concentrations in bronchoalveolar lavage fluid from infants who did or did not develop bronchopulmonary dysplasia (BPD and no $B P D$, respectively)

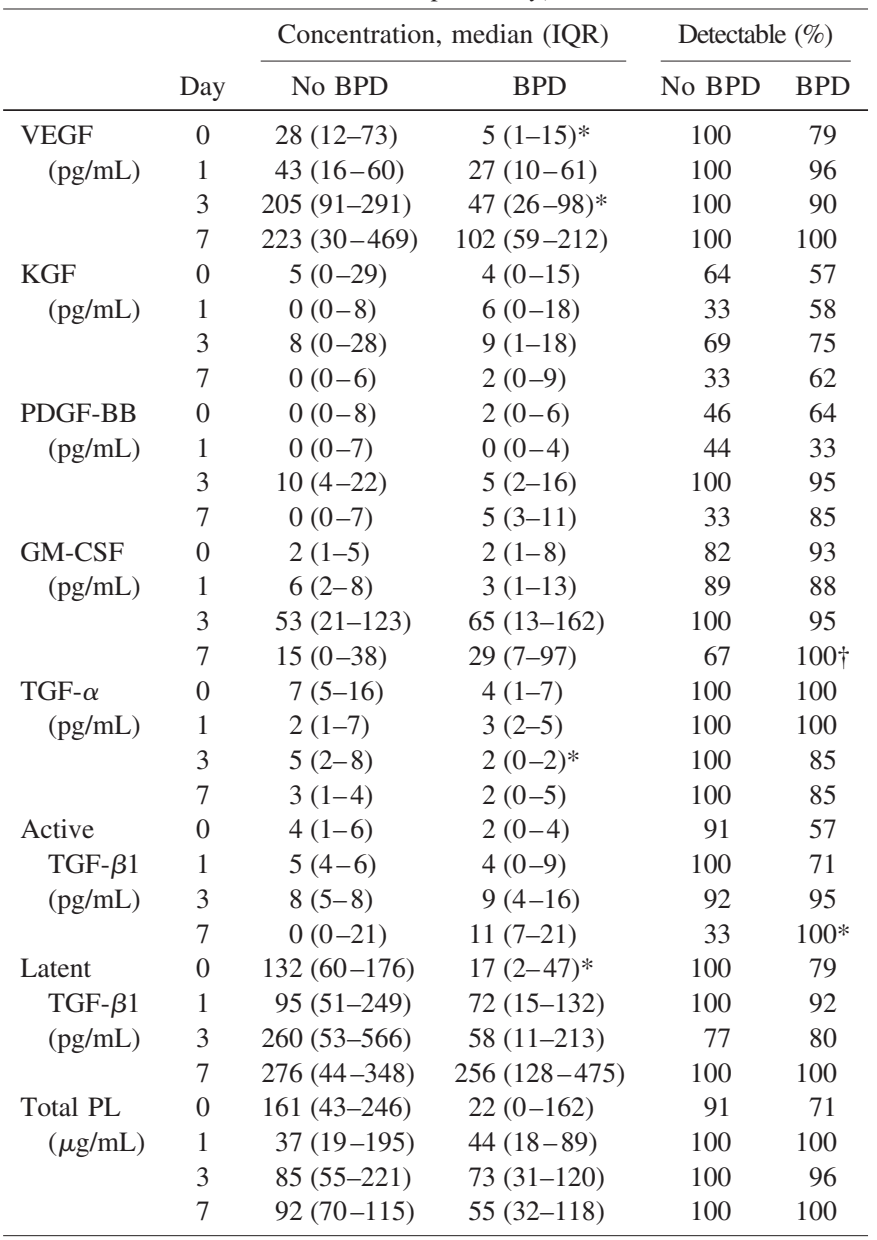

$* p<0.01$ vs no BPD.

$\dagger p<0.05$.

versus latent TGF- $\beta 1$ ratio on d 3 [mean $(\mathrm{CI})=0.06(0.02-$ $0.27)$ vs 0.01 (0.01-0.03); not shown]. Significant positive correlations were observed between BALF levels of several growth factors on each postnatal day (Table 3). Moreover, total PL correlated with levels of VEGF and both active and latent TGF- $\beta 1$ on several days.

Multivariable analyses-the marginal model. Figure 1 shows BALF growth factor and total PL concentrations as predicted by the marginal model for infants with BPD and those without. For ease of graphical display, model predicted values were transformed back to represent growth factor levels in picograms per milliliter. Model parameter estimates for each growth factor are shown in Table 4. For all marginal models, a diagonal covariance matrix of the outcome responses was selected as the most appropriate.

BPD was associated with increased GM-CSF but lower latent TGF- $\beta 1$ and total PL during the entire study period in these analyses (Fig. $1 D, E$, and $H$ ). For VEGF and TGF- $\alpha$, the interaction term $(\mathrm{BPD} \times$ time) was retained in the model because of its significant contribution, thus allowing for timedependent effect of BPD status on growth factor concentration (Table 4). Pairwise comparisons for individual time points showed BPD to be associated with decreased levels of both VEGF and TGF- $\alpha$ on d 0 and 3 [VEGF: mean difference (95\% CI) $=-1.75(-2.72,-0.77), p<0.001$; and $-1.18(-2.30$, -0.06 ), $p=0.04$, respectively (Fig. $1 A$ ); TGF- $\alpha$ : mean difference $(95 \% \mathrm{CI})=-0.73(-1.42,-0.04), p=0.04$; and -1.01 ( $-1.64,-0.38), p=0.003$, respectively (Fig. 1E)]. Marginal model analysis showed no significant association between BPD and BALF concentrations of KGF, PDGF-BB, and active TGF- $\beta$.

From the marginal model analyses, several other variables emerged as significant independent predictors of bronchoalveolar growth factor concentrations (Table 4). KGF and VEGF concentrations were shown to increase with advancing gestational age. Conversely, preeclampsia was associated with decreased VEGF, KGF, and GM-CSF. Both antenatal steroid exposure $>7 \mathrm{~d}$ before birth and exposure to high fraction of inspired oxygen were associated with increased levels of PDGF-BB. Importantly, no explanatory variable was associated with whether data were missing (BALF not obtained).

Multivariate analyses-ROC curves. Development of BPD was best predicted using a combination of VEGF and TGF- $\alpha$ levels on $\mathrm{d} 0$ [area under the ROC curve $(\mathrm{AUC})=0.92$ $(0.82-1.03) ; p<0.001]$. A slightly lower predictive value was obtained using VEGF, TGF- $\alpha$, and latent TGF- $\beta 1$ levels on $\mathrm{d}$ 3 (AUC $=0.88(0.74-1.01) ; p<0.001)$. The best single predictor was VEGF on d 0 (AUC $=0.87, p=0.002)$.

\section{DISCUSSION}

We describe the dynamic patterns of various growth factors and total PL in BALF during the first postnatal week in ventilated preterm infants. Distinct expression patterns were observed for different growth factors. Substantial differences in BALF growth factor concentrations were present during the first postnatal week between infants who developed BPD and those who did not. Moreover, it was shown that VEGF concentrations entail important predictive value for BPD development already within $24 \mathrm{~h}$ after birth.

The most prominent differences in BALF concentrations between infants with and without BPD were observed for VEGF. In the lung, VEGF is produced by endothelial cells as well as bronchial and type II alveolar epithelial cells $(3,8)$. Inhibition of VEGF during lung development results in disruption of vascular and alveolar development and a pathologic picture similar to that of new BPD (8). Thus, the lower initial VEGF concentrations found in our study in infants eventually developing BPD could well reflect a mechanistic process of adverse lung development and are in agreement with previous human studies $(22,23)$. BALF VEGF levels may be used to identify individuals at particular risk for BPD at an early stage, which could facilitate future implementation of individualized preventive strategies for BPD in preterm infants.

Moreover, VEGF may be a marker of lung development, supported by the positive association between VEGF and gestational age, and the correlation between VEGF and PL concentrations in BALF. The latter observation corresponds to animal experimental evidence indicating a stimulatory effect 
Table 3. Significant correlations between bronchoalveolar lavage levels of individual growth factors and total phospholipids (PL) on different postnatal days

\begin{tabular}{|c|c|c|c|c|c|c|c|c|}
\hline & Day & Latent TGF- $\beta 1$ & Active TGF- $\beta 1$ & TGF- $\alpha$ & GM-CSF & PDGF-BB & KGF & VEGF \\
\hline \multirow[t]{4}{*}{ Total PL } & 0 & $0.34 *$ & $0.25 \dagger$ & $0.19 \ddagger$ & - & - & - & - \\
\hline & 1 & - & - & - & - & - & - & - \\
\hline & 3 & - & - & - & - & - & - & $0.13 \ddagger$ \\
\hline & 7 & $0.56 \dagger$ & - & - & - & - & - & $0.38 \ddagger$ \\
\hline \multirow[t]{4}{*}{ VEGF } & 0 & $0.36^{*}$ & $0.29 \dagger$ & $0.13 \ddagger$ & - & - & $0.18 \ddagger$ & \\
\hline & 1 & $0.15 \ddagger$ & $0.14 \div$ & $0.14 \ddagger$ & - & - & - & \\
\hline & 3 & $0.12 \ddagger$ & - & $0.24 \dagger$ & $0.24 \dagger$ & $0.20 \dagger$ & - & \\
\hline & 7 & $0.48 \dagger$ & $0.25 \ddagger$ & - & $0.62 *$ & - & - & \\
\hline \multirow[t]{4}{*}{ KGF } & 0 & $0.17 \ddagger$ & $0.22 \dagger$ & $0.25 \dagger$ & - & $0.25 \dagger$ & & \\
\hline & 1 & - & - & - & - & - & & \\
\hline & 3 & - & - & - & $0.27 \dagger$ & $0.46^{*}$ & & \\
\hline & 7 & - & - & - & - & $0.36 \neq$ & & \\
\hline \multirow[t]{4}{*}{ PDGF-BB } & 0 & - & $0.14 \ddagger$ & $0.31 \dagger$ & - & & & \\
\hline & 1 & $0.23 \dagger$ & - & $0.48^{*}$ & - & & & \\
\hline & 3 & - & - & - & $0.38^{*}$ & & & \\
\hline & 7 & - & $0.48 \dagger$ & - & - & & & \\
\hline \multirow[t]{4}{*}{ GM-CSF } & 0 & - & - & - & & & & \\
\hline & 1 & - & - & - & & & & \\
\hline & 3 & - & - & - & & & & \\
\hline & 7 & $0.28 \ddagger$ & $0.43 \dagger$ & - & & & & \\
\hline \multirow[t]{4}{*}{ TGF- $\alpha$} & 0 & $0.62 *$ & $0.15 \dagger$ & & & & & \\
\hline & 1 & $0.60^{*}$ & $0.14 \div$ & & & & & \\
\hline & 3 & $0.38^{*}$ & - & & & & & \\
\hline & 7 & - & - & & & & & \\
\hline \multirow[t]{4}{*}{ Active TGF- $\beta 1$} & 0 & $0.32 \dagger$ & & & & & & \\
\hline & 1 & $0.44^{*}$ & & & & & & \\
\hline & 3 & - & & & & & & \\
\hline & 7 & $0.39 \dagger$ & & & & & & \\
\hline
\end{tabular}

Numbers represent $R^{2}$ values.

$* p<0.001$.

$\dagger p<0.01$.

$\ddagger p<0.05$.

of VEGF on pulmonary surfactant synthesis $(24,25)$. The association between lower alveolar VEGF and total PL concentrations and subsequent BPD development supports the concept that a developmental arrest of the lung is a critical mechanism in the development of new BPD (2).

Besides VEGF and PL, TGF- $\alpha$ was also decreased in infants developing BPD. We are unaware of earlier reports of TGF- $\alpha$ quantification in BALF from preterm infants. Given the low overall levels, reducing accuracy of the measurements, it is surprising that significant differences were detected. TGF- $\alpha$ is a known stimulant of angiogenesis and alveolar epithelial differentiation. Pulmonary overexpression of TGF- $\alpha$ disrupts lung morphology in mice (14), while paradoxically TGF- $\alpha$ knockout also results in a reduction of the terminal gas exchange area (26). The latter corresponds to our findings of reduced TGF- $\alpha$ being associated with the development of BPD. Together, the available data on the role of TGF- $\alpha$ within the lung indicate that tight regulation of its expression is vital for proper lung development.

GM-CSF is a stimulator of proliferation and differentiation of granulocytes and macrophages, and a regulator of surfactant homeostasis $(12,13)$. GM-CSF overexpression leads to exaggerated macrophage proliferation and activation (27), while GM-CSF null mice experience excessive accumulation of surfactant constituents in the alveolar space (28). The sudden increase in BALF levels of GMCSF by the third postnatal day as found in our study is in line with earlier reports (29). We hypothesize that the increase in GM-CSF in infants developing BPD is a marker of increased influx and activation of inflammatory cells in the alveolar space.

TGF- $\beta 1$ is an ubiquitous regulator of embryonic development. It is secreted as an inactive precursor protein consisting of mature TGF- $\beta 1$ and the latency associated peptide (LAP) (16). Latent TGF- $\beta 1$ can be activated in various ways, including by acidification as performed in this study (16). Our study shows that in ventilated preterm newborns, the inactive precursor protein comprises the vast majority of TGF- $\beta 1$ in the alveolar space. Why such an abundance of the latent TGF- $\beta 1$ form is present in the lung remains unknown, although our data indicate that increased TGF- $\beta 1$ activation may be implicated in the pathophysiology of BPD. TGF- $\beta 1$ overexpression decreases alveolarization in newborn murine models on the one hand (17), whereas TGF- $\beta 1$ diminishes apoptosis and promotes repair in alveolar type II cells after hyperoxia (30). The ambivalent nature of TGF- $\beta 1$ in pulmonary physiology complicates interpretation of its contribution to BPD development.

Earlier reports indicate a role in the pathogenesis of BPD for TGF- $\beta$ and other classic growth factors involved in fibrosis and lung repair such as PDGF-BB and $\operatorname{KGF}(3,6)$. In this 

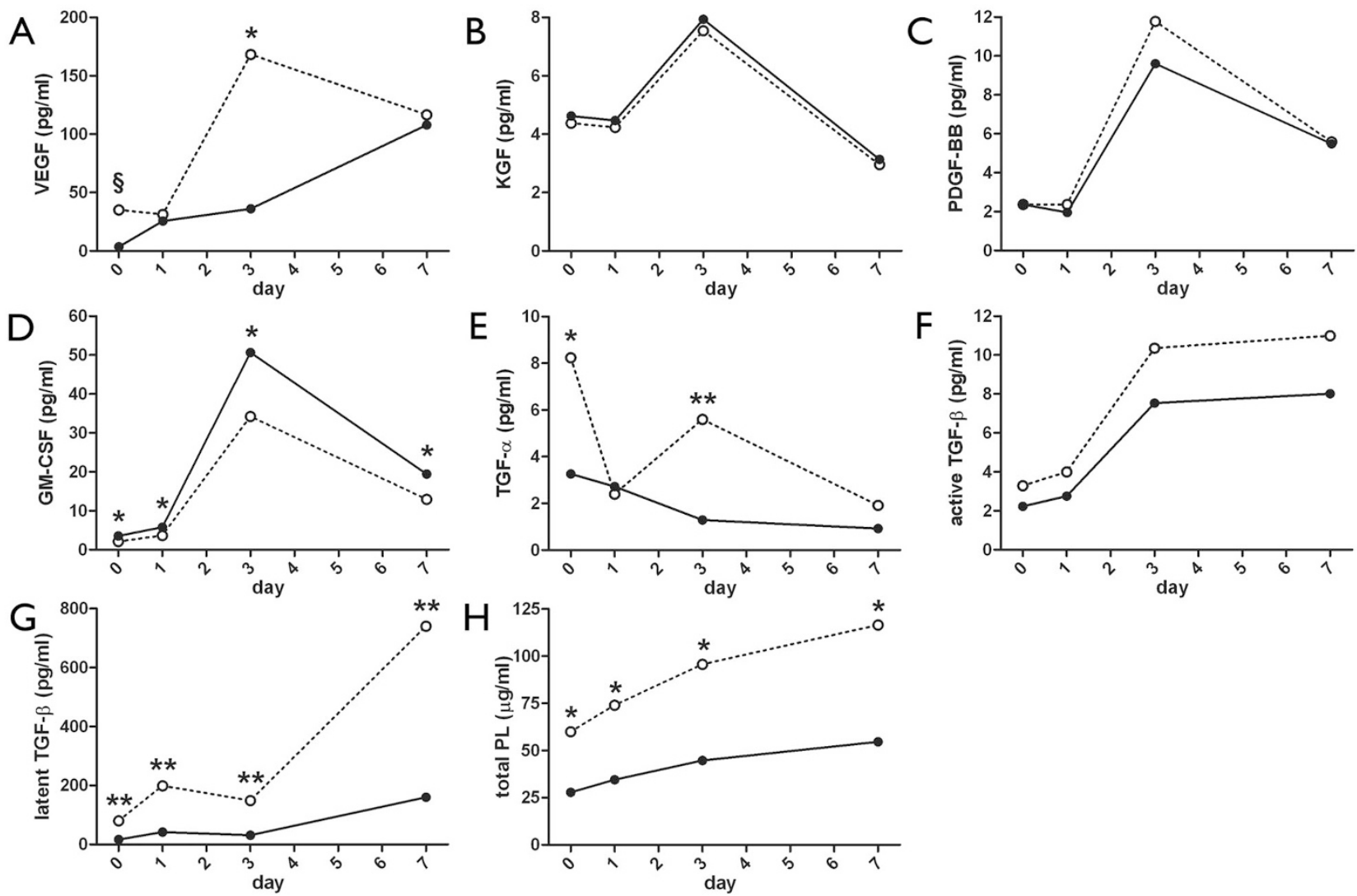

Figure 1. $(A-H)$ : Temporal growth factor and total PL patterns in bronchoalveolar lavage fluid for infants developing bronchopulmonary dysplasia (BPD; continuous line $)$ and infants surviving without $\mathrm{BPD}(\bigcirc$, dashed line $)$ as predicted by the marginal models with adjustment for confounders. Points represent mean predictives, and $p$ values relate to the model estimate for the BPD effect (Table $3 ; * p<0.05$ and $* * p<0.01$ for individual time points).

study, we were unable to reproduce previous associations between BALF levels of these factors and development of BPD in multivariable analysis. Instead, significant associations were detected between BPD and levels of total PL and growth factors involved in lung maturation and development (e.g., VEGF and TGF- $\alpha$ ). These findings are in agreement with the current concept of a shift in pathophysiology from old to new BPD $(2,4)$. Secondary lung injury and fibrosis are replaced by a picture depicted as a developmental arrest of the lung. Although, to date, the pathophysiology of this change has primarily been studied in animals, this study provides an additional supportive evidence of a molecular basis for this shift in humans.

Positive correlations were observed between individual levels of various growth factors on each day, in line with earlier studies in TAF (31), suggesting important interaction or costimulation. Moreover, it was striking to see a strong negative correlation between preeclampsia and almost any growth factor in BALF after multivariable adjustment. Interpretation of this association is complicated, because preeclampsia may be a proxy for being small for gestational age as well as for absence of chorioamnionitis (5). Both factors are associated with changes in growth factor expression as well as BPD risk (5). Additional studies are needed to explore the effect of maternal preeclampsia on fetal lung development and growth factor expression.

Particular strengths of this study include the simultaneous quantification of several growth factors in one pop- ulation and the application of a marginal model approach. The former enables a composite picture of the several growth factors to be obtained, to find possible differential expression patterns. The latter allows for temporal comparisons of mean changes in growth factor concentrations with adjustment for potential confounders. It is important to emphasize that the model parameters and associated conclusions are only valid under the condition that, given all relevant covariates, missingness occurred at random. We had no apparent reason to dismiss this assumption, and as such we believe that the results are unbiased.

The underlying mechanisms responsible for the demonstrated effects were not studied and remain open to speculation. Similarly, alterations in growth factor expression observed in patients developing BPD do not provide information on the causality of this association. Additional research is needed to evaluate whether these alterations have a causal role in BPD development or are merely markers of the process of adverse lung development leading to BPD. The developmental regulation and differential temporal expression of certain growth factors in relation to BPD observed in this study suggest that time-dependent effects need consideration when designing additional studies.

In conclusion, we have described general postnatal dynamics of BALF levels of various growth factors important for lung development and studied simultaneously in ventilated preterm infants. Important differences in BALF growth factor expression over time were demonstrated between infants de- 
Table 4. Parameter estimates and CIs from the marginal models for individual growth factors and total PL in bronchoalveolar lavage fluid

\begin{tabular}{|c|c|c|c|c|}
\hline Parameter & VEGF & KGF & PDGF-BB & GM-CSF \\
\hline Intercept & $-0.82(-5.04,3.41)$ & $-4.68(-9.98,0.61)$ & $-1.55(-5.70,2.57)$ & $-1.58(-5.61,2.44)$ \\
\hline Day $1(v s \mathrm{~d} 0)$ & $-0.11(-1.21,0.98)$ & $-0.03(-0.89,0.84)$ & $0.01(-0.75,0.75)$ & $0.40(-0.22,1.02)$ \\
\hline Day $3(v s \mathrm{~d} 0)$ & $1.54(0.49,2.60) \dagger$ & $0.46(-0.41,1.34)$ & $1.29(0.50,2.08) \dagger$ & $2.44(1.71,3.17) \dagger$ \\
\hline Day 7 (vs d 0$)$ & $1.18(-0.58,2.94)$ & $-0.31(-1.19,0.58)$ & $1.08(-0.16,2.01)$ & $1.51(0.69,2.33) \dagger$ \\
\hline $\mathrm{BPD}$ & $-1.74(-2.72,-0.77) \dagger$ & $0.53(-0.15,1.21)$ & $-0.13(-0.70,0.43)$ & $0.69(0.13,1.25)^{*}$ \\
\hline $\mathrm{BPD} \times \mathrm{d} 1$ & $1.89(0.51,3.27) \dagger$ & - & - & - \\
\hline $\mathrm{BPD} \times \mathrm{d} 3$ & $0.57(-0.82,1.95)$ & - & - & - \\
\hline $\mathrm{BPD} \times \mathrm{d} 7$ & $2.01(0.01,4.01)^{*}$ & - & - & - \\
\hline $\begin{array}{l}\text { GA (per wk } \\
\text { increase) }\end{array}$ & $0.15(0.01,0.30)^{*}$ & $0.23(0.04,0.41)^{*}$ & $0.05(-0.09,0.26)$ & $0.10(-0.04,0.23)$ \\
\hline Chorioamnionitis & - & $-0.74(-1.52,0.04)$ & - & - \\
\hline Preeclampsia & $-0.93(-1.52,-0.34) \dagger$ & $-0.96(-1.66,-0.25) \dagger$ & $-0.63(-1.27,0.01)$ & $-1.09(-1.66,-0.53) \dagger$ \\
\hline $\begin{array}{l}\text { Antenatal steroids } \\
<24 \text { h before birth }\end{array}$ & - & - & $0.43(-0.32,1.17)$ & - \\
\hline $\begin{array}{l}\text { Antenatal steroids } \\
2-7 \mathrm{~d} \text { before birth }\end{array}$ & - & - & $0.46(-0.43,1.35)$ & - \\
\hline $\begin{array}{l}\text { Antenatal steroids } \\
>7 \mathrm{~d} \text { before birth }\end{array}$ & - & - & $1.25(0.44,1.35) \dagger$ & - \\
\hline $\mathrm{FiO}_{2}$ (per 0.1 increase) & 一 & - & $0.25(0.04,0.46)^{*}$ & 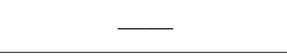 \\
\hline Parameter & TGF- $\alpha$ & Active TGF- $\beta 1$ & Latent TGF- $\beta 1$ & Total PL \\
\hline Intercept & $3.40(0.77,6.03)^{*}$ & $1.18(-2.84,5.20)$ & $1.62(-4.00,7.23)$ & $0.89(-3.52,5.29)$ \\
\hline Day $1(v s \mathrm{~d} 0)$ & $-1.00(-1.68,-0.31) \dagger$ & $0.15(-0.38,0.69)$ & $0.90(0.03,1.77)^{*}$ & $0.21(-0.78,1.19)$ \\
\hline Day $3(v s \mathrm{~d} 0)$ & $-0.34(-0.99,0.32)$ & $0.97(0.43,1.51) \dagger$ & $0.61(-0.47,1.69)$ & $0.46(-0.54,1.46)$ \\
\hline Day 7 (vs d 0$)$ & $-1.15(-2.32,-0.01)$ & $1.03(0.30,1.76) \dagger$ & $2.21(1.17,3.24) \dagger$ & $0.66(-0.35,1.66)$ \\
\hline BPD & $-0.73(-1.42,-0.04)^{*}$ & $-0.05(-0.54,0.43)$ & $-1.19(-1.87,-0.39) \dagger$ & $-0.64(-1.23,-0.05)^{*}$ \\
\hline $\mathrm{BPD} \times \mathrm{d} 1$ & $0.86(-0.02,1.75)$ & - & - & - \\
\hline $\mathrm{BPD} \times \mathrm{d} 3$ & $-0.29(-1.16,0.59)$ & - & - & - \\
\hline $\mathrm{BPD} \times \mathrm{d} 7$ & $0.36(-0.98,1.69)$ & - & - & - \\
\hline $\begin{array}{l}\text { GA (per wk } \\
\text { increase) }\end{array}$ & $-0.04(-0.13,0.05)$ & $0.01(-0.12,0.14)$ & $0.10(-0.10,0.29)$ & $0.11(-0.04,0.26)$ \\
\hline Chorioamnionitis & - & $-0.58(-1.17,0.01)$ & - & - \\
\hline Preeclampsia & $-0.33(-0.69,0.03)$ & - & $-1.33(-2.14,-0.51) \dagger$ & - \\
\hline $\begin{array}{l}\text { Antenatal steroids } \\
<24 \text { h before birth }\end{array}$ & - & $0.08(-0.60,0.76)$ & - & - \\
\hline $\begin{array}{l}\text { Antenatal steroids } \\
2-7 \mathrm{~d} \text { before birth }\end{array}$ & - & $-0.55(-1.28,0.17)$ & - & - \\
\hline $\begin{array}{l}\text { Antenatal steroids } \\
>7 \mathrm{~d} \text { before birth }\end{array}$ & - & $0.54(-0.19,1.27)$ & - & - \\
\hline $\mathrm{FiO}_{2}$ (per 0.1 increase) & - & - & - & - \\
\hline
\end{tabular}

Figures represent $\beta(95 \% \mathrm{CI})$ per unit increase for continuous factors or $v s$ the reference group for nominal factors.

$* p<0.05$.

$\dagger p<0.01$.

$\mathrm{FiO}_{2}$, fraction of inspired oxygen.

veloping BPD and healthy infants already from d 0 . Disturbance of the normal growth factor response to injury may explain part of the adverse lung development seen in BPD patients. Increased understanding of time dependent growth factor regulation of lung development may open up new perspectives for related interventions to prevent or treat BPD in the future.

\section{REFERENCES}

1. Northway WH Jr, Rosan RC, Porter DY 1967 Pulmonary disease following respirator therapy of hyaline-membrane disease. Bronchopulmonary dysplasia. N Engl J Med 276:357-368

2. Jobe AJ 1999 The new BPD: an arrest of lung development. Pediatr Res 46:641-643

3. Ambalavanan N, Carlo WA 2004 Bronchopulmonary dysplasia: new insights. Clin Perinatol 31:613-628

4. Kramer BW 2008 Antenatal inflammation and lung injury: prenatal origin of neonatal disease. J Perinatol 28:S21-S27

5. Been JV, Zimmermann LJ 2009 Histological chorioamnionitis and respiratory outcome in preterm infants. Arch Dis Child Fetal Neonatal Ed 94:F218-F225
6. Jankov RP, Tanswell AK 2004 Growth factors, postnatal lung growth and bronchopulmonary dysplasia. Paediatr Respir Rev 5:S265-S275

7. Dargaville PA, South M, McDougall PN 1999 Comparison of two methods of diagnostic lung lavage in ventilated infants with lung disease. Am J Respir Crit Care Med 160:771-777

8. Thebaud B, Abman SH 2007 Bronchopulmonary dysplasia: where have all the vessels gone? Roles of angiogenic growth factors in chronic lung disease. Am J Respir Crit Care Med 175:978-985

9. Ray P 2005 Protection of epithelial cells by keratinocyte growth factor signaling. Proc Am Thorac Soc 2:221-225

10. Yuan S, Hannam V, Belcastro R, Cartel N, Cabacungan J, Wang J, Diambomba Y, Johnstone L, Post M, Tanswell AK 2002 A role for platelet-derived growth factor-BB in rat postpneumonectomy compensatory lung growth. Pediatr Res 52:25-33

11. Hoyle GW, Li J, Finkelstein JB, Eisenberg T, Liu JY, Lasky JA, Athas G, Morris GF, Brody AR 1999 Emphysematous lesions, inflammation, and fibrosis in the lungs of transgenic mice overexpressing platelet-derived growth factor. Am J Pathol 154:1763-1775

12. Hamilton JA 2008 Colony-stimulating factors in inflammation and autoimmunity. Nat Rev Immunol 8:533-544

13. Trapnell BC, Whitsett JA 2002 Gm-CSF regulates pulmonary surfactant homeostasis and alveolar macrophage-mediated innate host defense. Annu Rev Physiol 64:775-802 
14. Kramer EL, Deutsch GH, Sartor MA, Hardie WD, Ikegami M, Korfhagen TR, Le Cras TD 2007 Perinatal increases in TGF- $\{$ alpha $\}$ disrupt the saccular phase of lung morphogenesis and cause remodeling: microarray analysis. Am J Physiol Lung Cell Mol Physiol 293:L314-L327

15. Strandjord TP, Clark JG, Guralnick DE, Madtes DK 1995 Immunolocalization of transforming growth factor-alpha, epidermal growth factor (EGF), and EGF-receptor in normal and injured developing human lung. Pediatr Res 38:851-856

16. Gordon KJ, Blobe GC 2008 Role of transforming growth factor-beta superfamily signaling pathways in human disease. Biochim Biophys Acta 1782:197-228

17. Gauldie J, Galt T, Bonniaud P, Robbins C, Kelly M, Warburton D 2003 Transfer of the active form of transforming growth factor-beta 1 gene to newborn rat lung induces changes consistent with bronchopulmonary dysplasia. Am J Pathol $163: 2575-2584$

18. Jobe AH, Bancalari E 2001 Bronchopulmonary dysplasia. Am J Respir Crit Care Med 163:1723-1729

19. Stewart JC 1980 Colorimetric determination of phospholipids with ammonium ferrothiocyanate. Anal Biochem 104:10-14

20. de Blic J, Midulla F, Barbato A, Clement A, Dab I, Eber E, Green C, Grigg J, Kotecha S, Kurland G, Pohunek P, Ratjen F, Rossi G 2000 Bronchoalveolar lavage in children. ERS Task Force on bronchoalveolar lavage in children. European Respiratory Society. Eur Respir J 15:217-231

21. Fitzmaurice G, Laird N, Ware J 2004 Applied Longitudinal Analysis. John Wiley \& Sons, Malden MA, p 536

22. Hasan J, Beharry KD, Valencia AM, Strauss A, Modanlou HD 2009 Soluble vascular endothelial growth factor receptor 1 in tracheal aspirate fluid of preterm neonates at birth may be predictive of bronchopulmonary dysplasia/chronic lung disease. Pediatrics 123:1541-1547

23. Lassus P, Turanlahti M, Heikkila P, Andersson LC, Nupponen I, Sarnesto A, Andersson S 2001 Pulmonary vascular endothelial growth factor and Flt-1 in fetuses, in acute and chronic lung disease, and in persistent pulmonary hypertension of the newborn. Am J Respir Crit Care Med 164:1981-1987
24. Been JV, Zoer B, Kloosterboer N, Kessels CG, Zimmermann LJ, Van Iwaarden JF, Villamor E 2009 Pulmonary vascular endothelial growth factor expression and disaturated phospholipid content in a chicken model of hypoxia-induced fetal growth restriction. Neonatology 97:183-189

25. Compernolle V, Brusselmans K, Acker T, Hoet P, Tjwa M, Beck H, Plaisance S, Dor Y, Keshet E, Lupu F, Nemery B, Dewerchin M, Van Veldhoven P, Plate K, Moons L, Collen D, Carmeliet P 2002 Loss of HIF-2alpha and inhibition of VEGF impair fetal lung maturation, whereas treatment with VEGF prevents fatal respiratory distress in premature mice. Nat Med 8:702-710

26. Minami S, Iwamoto R, Mekada E 2008 HB-EGF decelerates cell proliferation synergistically with TGFalpha in perinatal distal lung development. Dev Dyn 237:247-258

27. Metcalf D, Moore JG 1988 Divergent disease patterns in granulocyte-macrophage colony-stimulating factor transgenic mice associated with different transgene insertion sites. Proc Natl Acad Sci USA 85:7767-7771

28. Dranoff G, Crawford AD, Sadelain M, Ream B, Rashid A, Bronson RT, Dickersin GR, Bachurski CJ, Mark EL, Whitsett JA 1994 Involvement of granulocytemacrophage colony-stimulating factor in pulmonary homeostasis. Science 264:713716

29. Bry K, Hallman M, Teramo K, Waffarn F, Lappalainen U 1997 Granulocytemacrophage colony-stimulating factor in amniotic fluid and in airway specimens of newborn infants. Pediatr Res 41:105-109

30. Buckley S, Shi W, Barsky L, Warburton D 2008 TGF-beta signaling promotes survival and repair in rat alveolar epithelial type 2 cells during recovery after hyperoxic injury. Am J Physiol Lung Cell Mol Physiol 294:L739-L748

31. Vento G, Matassa PG, Ameglio F, Capoluongo E, Zecca E, Tortorolo L, Martelli M, Romagnoli C 2005 HFOV in premature neonates: effects on pulmonary mechanics and epithelial lining fluid cytokines. A randomized controlled trial. Intensive Care Med 31:463-470 